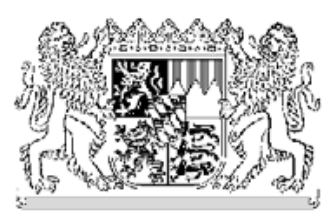

\title{
Grußwort des Bayerischen Staatsministers für Bildung und Kultus, Wissenschaft und Kunst, Dr. Ludwig Spaenle, zum 65. Geburtstag von Dr. Rolf Griebel
}

Die Bayerische Staatsbibliothek hat in den vergangenen Jahren unter Herrn Generaldirektor Dr. Griebel historische Herausforderungen gemeistert. Sie hat ihr Selbstverständnis neu definiert und an die gesellschaftlichen Anforderungen der Zukunft angepasst. In einer enormen Kraftanstrengung hat sie sich $\mathrm{zu}$ einer multimedialen Serviceeinrichtung und einem Innovationszentrum für digitale Informationstechnologie mit hoher nationaler und internationaler Strahlkraft gewandelt. Damit hat Herr Dr. Griebel gezeigt, welche Gestaltungskraft eine Fachbehörde entfalten kann, die sich auf ihre genuinen Stärken und Alleinstellungsmerkmale konzentriert.

Die Grundlage für diesen Erfolg bildet die bewusste Entscheidung, trotz angespannter Haushaltslage und eingeschränkter personeller Ressourcen die eigene Leistung weiter zu steigern. Voraussetzung dafür ist ein Führungsstil, der sich an den Potentialen der Mitarbeiterinnen und Mitarbeiter orientiert und sie ganz zur Entfaltung bringen möchte. Hinzu kommt eine moderne Öffentlichkeitsarbeit, die das attraktive Angebot der Staatsbibliothek überzeugend kommuniziert.

In der „Ära Griebel“ beschreitet die Bayerische Staatsbibliothek völlig neue Wege, wenn es darum geht, unser kulturelles Erbe in Bayern zu bewahren und zu vermitteln. So digitalisiert sie in einem bahnbrechenden Public-Private-Partnership-Projekt mit dem Internetkonzern Google ihre urheberrechtsfreien Bestände aus dem 17. bis 19. Jahrhundert. Mit Internetauftritten wie dem bavarikon und dem Literaturportal Bayern sowie mit einer ganzen Serie von Apps zeigt sie beispielhaft, wie zeitgemäß das bayerische Bibliothekswesen längst aufgestellt ist.

Die Bayerische Staatsbibliothek ist ein einzigartiger Gedächtnisspeicher und zugleich eine der zentralen Bildungseinrichtungen unseres Landes. Sie ist ein wichtiger Dienstleister für Wissenschaft und Forschung und vermittelt Schülern und Studierenden, wie Informationen effizient $\mathrm{zu}$ recherchieren sind. Als Bildungs- und Wissenschaftsminister freue ich mich, wie umfassend und erfolgreich die Bayerische Staatsbibliothek diese zentralen Aufgaben wahrnimmt.

Generaldirektor Dr. Griebel hat in allen skizzierten Handlungsfeldern Enormes geleistet. Er hat es sich geradezu zu seiner Lebensaufgabe gemacht, „seine“ Baye- 
rische Staatsbibliothek weiterzuentwickeln. Besonders schätze ich seine visionäre Kraft und seine Fähigkeit, mit strategischer Planung diese Visionen zu realisieren.

So überbringe ich Ihnen, sehr geehrter Herr Dr. Griebel, zu Ihrem 65. Geburtstag meine herzlichsten Glück- und Segenswünsche.

München, im Januar 2014

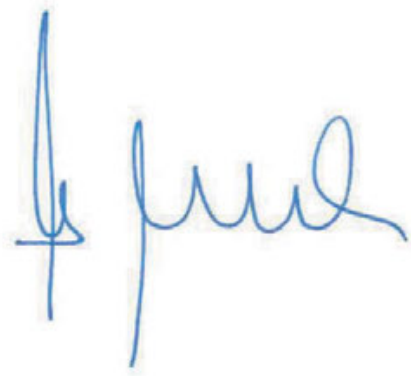

Dr. Ludwig Spaenle

Bayerischer Staatsminister

für Bildung und Kultus, Wissenschaft und Kunst

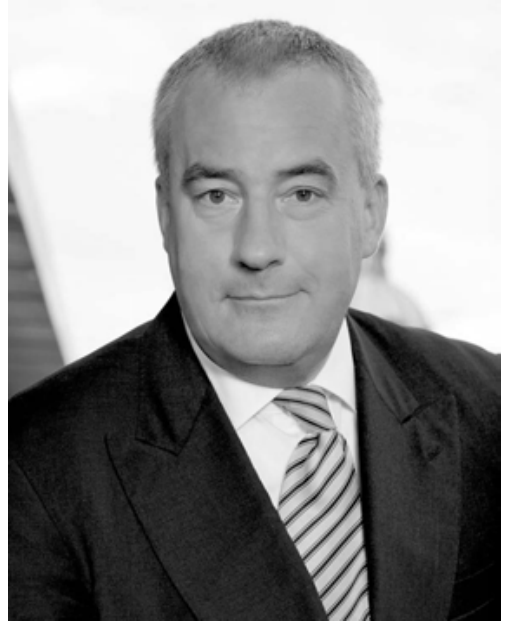

